\title{
Os Impactos da Reengenharia no processo de compensação de cheques: Estudo em uma Instituição Financeira
}

\begin{abstract}
João Marinho de Oliveira Filho
Centro Universitário Estácio do Ceará

E-mail:mmarinho_adm@hotmail.com

Rosângela Venâncio Nunes Mestrado em Logística e Pesquisa Operacional pela Universidade Federal do Ceará UFC

Professora do Centro Universitário Estácio do Ceará Rua Vicente Linhares, 308. Aldeota. Fortaleza/CE. CEP: 60135-270 E-mail: angelnuness@gmail.com

Charles Washington Costa de Assis Especialização em Auditoria pelo Centro Universitário Estácio do Ceará Professor do Centro Universitário Estácio do Ceará Rua Vicente Linhares, 308. Aldeota. Fortaleza/CE. CEP: 60135-270 E-mail: charles-cont@hotmail.com

Rita de Cássia Fonseca Mestrado em Engenharia de Produção pela Universidade Tecnológica Federal do Paraná - UTFPR Professora da Universidade Estadual do Centro Oeste - UNICENTRO Rua Padre Honorino João Muraro, 875. Santa Cruz. Guarapuava/PR. CEP: 85.015-430 E-mail: ritadecfonseca@hotmail.com
\end{abstract}

\section{RESUMO}

Este artigo consiste na análise dos impactos da reengenharia no processo de compensação de cheques em uma instituição financeira. Os objetivos específicos estão focados em conceitos relevantes sobre gestão de processos, reengenharia de processos, avaliação de desempenho e os impactos da reengenharia na avaliação de desempenho. Metodologicamente utilizou-se o método dedutivo e o indutivo, com abordagem quantitativa, de natureza aplicada e procedimento técnico documental. Por meio desse estudo, pôde-se concluir que é de fundamental importância medir os impactos de qualquer mudança organizacional, pois, desta forma, é possível observar tendências, auxiliando o gerenciamento dos processos-chave que agregam valor aos clientes.

Palavras-chave: Gestão de processos. Reengenharia de processos. Avaliação de desempenho. Compensação de cheques em Instituição Financeira. 
Os Impactos da Reengenharia no processo de compensação de cheques: Estudo em uma

Instituição Financeira

João Marinho de Oliveira Filho, Rosângela Venâncio Nunes, Charles Washington Costa de Assis, Rita de

Cássia Fonseca

The Impacts of Reengineering in the process of checks compensation in a Financial Institution

\section{ABSTRACT}

This article analyses the impacts of the reengineering in the process of checks compensation in a financial institution. Therefore, the specific objectives are focused on relevant concepts like process management, process reengineering, performance evaluation, and the impact of reengineering on performance evaluation. Methodologically we used inductive and deductive methods, in a quantitative approach, using documentary procedure. With the study we could conclude that it is very important to measure the impact of any organizational change, because it is possible to observe trends, assisting managers with key processes that add value to customers.

Keywords: Process management. Reengineering processes. Performance evaluation. Compensation checks in a Financial Institution.

\section{INTRODUÇÃO}

Ter a percepção da necessidade de analisar ou medir um conjunto de atividades relevantes na organização não é uma tarefa simples para gestores, estudantes e demais atores do mundo organizacional. Porém, atualmente tem sido notório que esses agentes procuram cada vez mais temas que possibilitem avaliar de fato os processos empresariais e, se necessário, executar as devidas mudanças, a fim de que elas proporcionem diferencial competitivo para suas empresas e agreguem valor na percepção de seus clientes e investidores.

Dentre os temas que ganham destaque no meio organizacional, tem-se a gestão de processos, que busca definir, documentar e gerir passos de uma tarefa ou o conjunto delas, de modo que tais modelos estabelecidos possam auxiliar no planejamento e na execução das atividades ou serviços. Após consolidada essa predefinição, a gestão de processos ainda dispõe de outro modelo, a reengenharia de processos, que propõe a revisão do que está sendo feito, incidindo na avaliação dos métodos e relacionando-os aos objetivos estabelecidos, sendo ainda capaz de sugerir possíveis reformulações. 
Os Impactos da Reengenharia no processo de compensação de cheques: Estudo em uma Instituição Financeira João Marinho de Oliveira Filho, Rosângela Venâncio Nunes, Charles Washington Costa de Assis, Rita de Cássia Fonseca

Todo processo deve sujeitar-se à análise como forma de medir seu desempenho, e para isso deve-se usar a avaliação de desempenho mediante a definição de indicadores de desempenho, que por sua vez são capazes de mensurar o nível de rendimento quanto à qualidade, o tempo, à produtividade, entre outros.

No caso das instituições de intermediação financeira no Brasil, estas são caracterizadas pelo ambiente competitivo que constituem, exigindo que tenham capacidade de adaptação rápida às exigências oriundas dos diversos meios, principalmente das legislações e do subsistema normativo, que é responsável por formular as políticas e fiscalizar os demais órgãos do sistema.

Diante disso, as instituições financeiras tiveram que realizar a reengenharia de seus processos para se encaixar adequadamente às determinações do BACEN, surgindo daí a questão dos impactos que a reestruturação geraria no desempenho desses processos. Diante disso, surge a seguinte questão problema: Quais são os impactos da reengenharia no processo de compensação de cheques em uma instituição financeira? Assim, o estudo objetiva analisar os impactos da reengenharia no processo de compensação de cheques em uma instituição financeira.

Como objetivos específicos vinculados ao objetivo geral tem-se: conceituar gestão por processos, expondo suas características e sua importância nas organizações; discorrer sobre reengenharia de processos, relatando suas características e objetivos; identificar o que é avaliação de desempenho e apresentar os possíveis impactos da reengenharia no desempenho; e discorrer sobre o processo de compensação de cheques no Brasil, evidenciando seus participantes, bem como suas atividades.

Este estudo parte da ideia de que ao realizar mudança no processo, a instituição conseguirá mitigar inconsistências, reduzir custos logísticos e operacionais, diminuir o tempo de resposta de compensação de cheques. Logo, o processo de compensação de cheques teria uma melhoria significativa no seu desempenho. A escolha do tema deuse a partir da relevância de medir os resultados após a mudança no processo de compensação de cheques, uma vez que inoperâncias foram mapeadas. Deu-se também pelos processos que envolvem diversos recursos e que têm a missão de 
Os Impactos da Reengenharia no processo de compensação de cheques: Estudo em uma Instituição Financeira João Marinho de Oliveira Filho, Rosângela Venâncio Nunes, Charles Washington Costa de Assis, Rita de Cássia Fonseca

atender os objetivos da atividade fim nas organizações, além de focar em outros temas que vêm ganhando destaque entre administradores e estudantes de administração nas últimas décadas, como: "gestão de processos", "reengenharia de processos" e "avaliação de desempenho".

O artigo estrutura-se em cinco seções, a saber: introdução, referencial teórico, procedimentos metodológicos utilizados no estudo, apresentação e análise dos dados e considerações finais, seguidas das referências.

\section{REFERENCIAL TEÓRICO}

O referencial teórico que compõe a estudo trata dos seguintes tópicos: gestão de processos, reengenharia de processos, avaliação e desempenho; impactos da reengenharia na avaliação de desempenho.

\subsection{Gestão de processos: características e importância}

Os processos organizacionais englobam atividades coordenadas que envolvem pessoas, recursos, procedimentos e tecnologias. Logo, sempre que o tema entra em destaque nas empresas, também surge o argumento da complexidade de se conciliar vários componentes que interagem no cotidiano empresarial com propósitos de atender os objetivos já definidos.

Ultimamente, parte dos gestores estão percebendo a importância deste novo modelo, a gestão de processos, para garantir benefícios relacionados à imagem da empresa, aos produtos/ serviços e à otimização de seus recursos, nas atividades que podem agregar ou mitigar o valor percebido pelo cliente. Diversas abordagens definem gestão de processos (Business Process Management - BPM), como um conjunto de atividades que visam principalmente atingir os objetivos da atividade-fim da organização.

Maximiano (2012, p.325) argumenta que é por meio do processo que a organização recebe recursos do ambiente (trabalho humano, tecnologia, materiais, 
Os Impactos da Reengenharia no processo de compensação de cheques: Estudo em uma Instituição Financeira João Marinho de Oliveira Filho, Rosângela Venâncio Nunes, Charles Washington Costa de Assis, Rita de Cássia Fonseca

equipamentos), e os transforma em produtos, serviços e informações que são devolvidos ao ambiente. Davenport (1998 apud ARAÚJO, 2011) afirma que processo é a ordenação específica das atividades de trabalho, com um começo, um fim, entradas e saídas claramente identificadas.

Para Hammer e Champy (1993 apud CHIAVENATO, 1994), processo empresarial é um grupo de atividades realizadas numa sequência lógica, com o objetivo de produzir um bem ou serviço que tenha valor específico para um grupo de clientes. Os autores destacam a relação entre processos e clientes, relevando a importância do tema para as organizações. Oliveira (2008) ressalta que tal ordenação tem a finalidade de atender e preferencialmente suplantar as necessidades dos clientes externos e internos da empresa.

Com relação aos processos e sua gestão, Araújo (2011, p.26) contextualiza sistematicamente gestão de processos:

[...] atividades referem-se às tarefas executadas por pessoas ou máquinas com intuito de transformar um insumo num produto que deverá sofrer transformação por outra atividade e assim sucessivamente, compondo um processo [...] já sabendo o que significa processo, para uma melhor compreensão, é viável a elaboração de fluxogramas, estes que por sua vez apresentam o processo passo a passo, ação por ação [...] adoção de indicadores de desempenho a fim de descobrir inconsistências, mitigar gargalos ou resolver demais problemas no fluxo [...] a gestão de processo deve ter seu início provocado por equipes formadas especificamente para esse fim, assim a organização pode ter mais segurança em todas as ações do grupo [...] tal visão determina que os processos são envolvidos por várias células de trabalho, para tanto 0 compromisso destes setores com todo processo é essencial.

Oliveira (2008) acredita que a utilização do termo "modelo de gestão organizacional com foco nos processos", torna mais fácil o entendimento dos seus aspectos. O autor menciona que a empresa nada mais é do que um sistema de entradas e saídas de pessoas, recursos, dados, informações e que a "BPM" tem o 
Os Impactos da Reengenharia no processo de compensação de cheques: Estudo em uma Instituição Financeira João Marinho de Oliveira Filho, Rosângela Venâncio Nunes, Charles Washington Costa de Assis, Rita de Cássia Fonseca

intuito de integrar tais componentes para minimizar o uso dos recursos, porém com grande capacidade produtiva.

Já Sordi (2005) aborda a gestão de processos de negócio como um meio integrador dos departamentos envolvidos nas atividades. O autor cita, por exemplo, recursos humanos, papéis e responsabilidades, estruturas organizacionais, políticas e regras, tecnologias (comunicação, facilidades e computação) e conhecimento. Reforça também o modelo horizontal de gestão, admitindo que quanto mais plana for a estrutura, menos complexo será seu gerenciamento e maior será o seu controle.

Para uma melhor compreensão, na Figura 1 apresenta-se de forma esquematizada a hierarquia dos processos em seus níveis de execução e de gerenciamento.

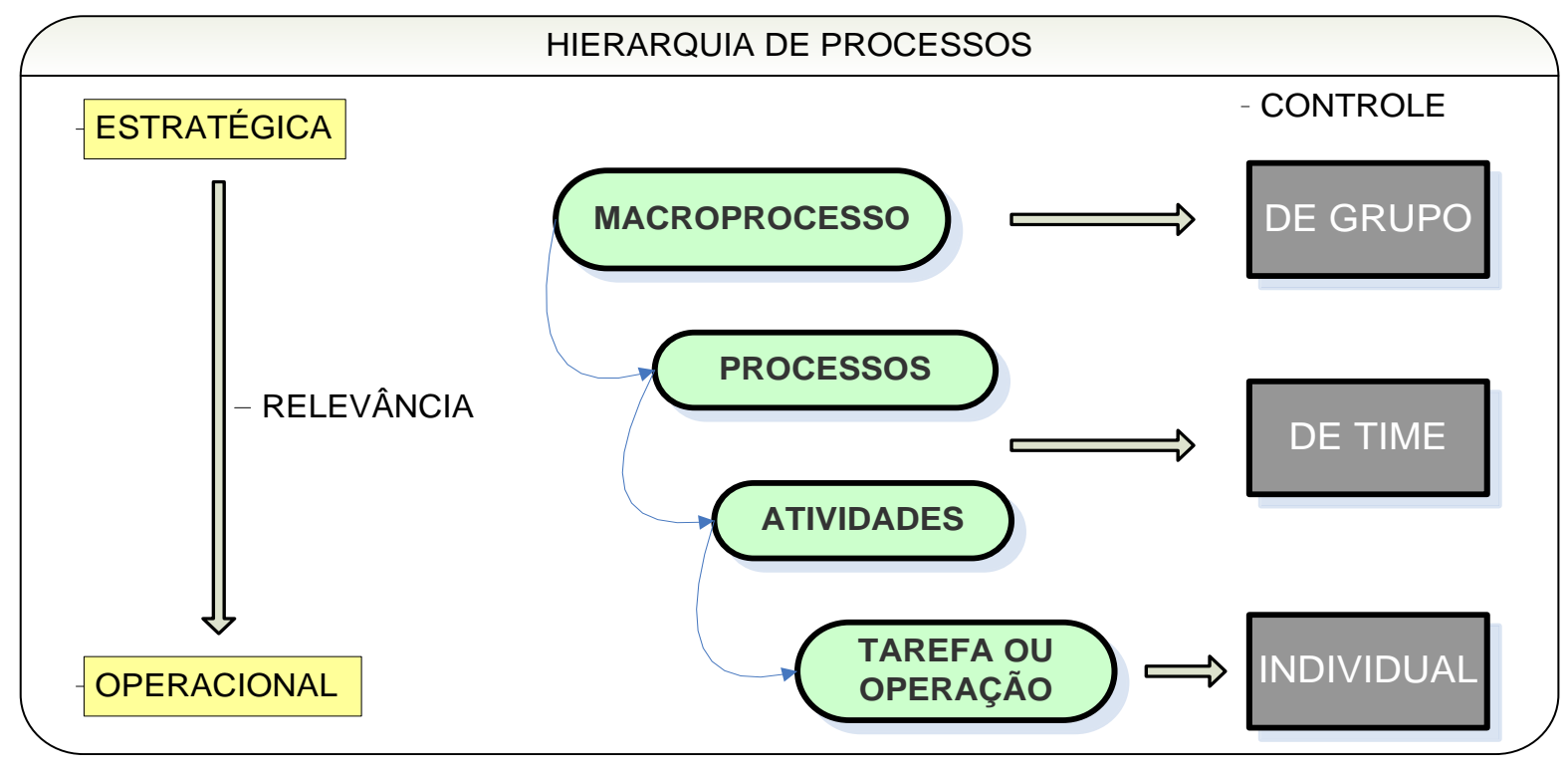

Figura 1: Hierarquia de processos Fonte: Adaptado de Campos (1998, p.127).

A figura mostra a interligação dos processos, passando desde os macroprocessos, que representam o processo-chave para a finalidade e junção dos 
Os Impactos da Reengenharia no processo de compensação de cheques: Estudo em uma Instituição Financeira João Marinho de Oliveira Filho, Rosângela Venâncio Nunes, Charles Washington Costa de Assis, Rita de Cássia Fonseca

outros processos, que são formados por um conjunto de atividades, cujas tarefas e operações as compõem.

Campos (1998) explica que quando a empresa utiliza a hierarquia de processos apresentada na Figura 1, consegue facilitar o gerenciamento no cotidiano, internalizando macroprocessos, processos e atividades, dividindo bem as responsabilidades de cada área, bem como a importância no conjunto.

Para Maximiano (2012, p.326), a administração de processo consiste em gerir as funções permanentes como elos de uma corrente, não como departamento isolado. $\mathrm{O}$ resultado é uma cadeia horizontal de processos, em lugar de uma estrutura que não integrava os setores. A Figura 2 representa um exemplo dos processos numa visão horizontal integrado por vários setores.

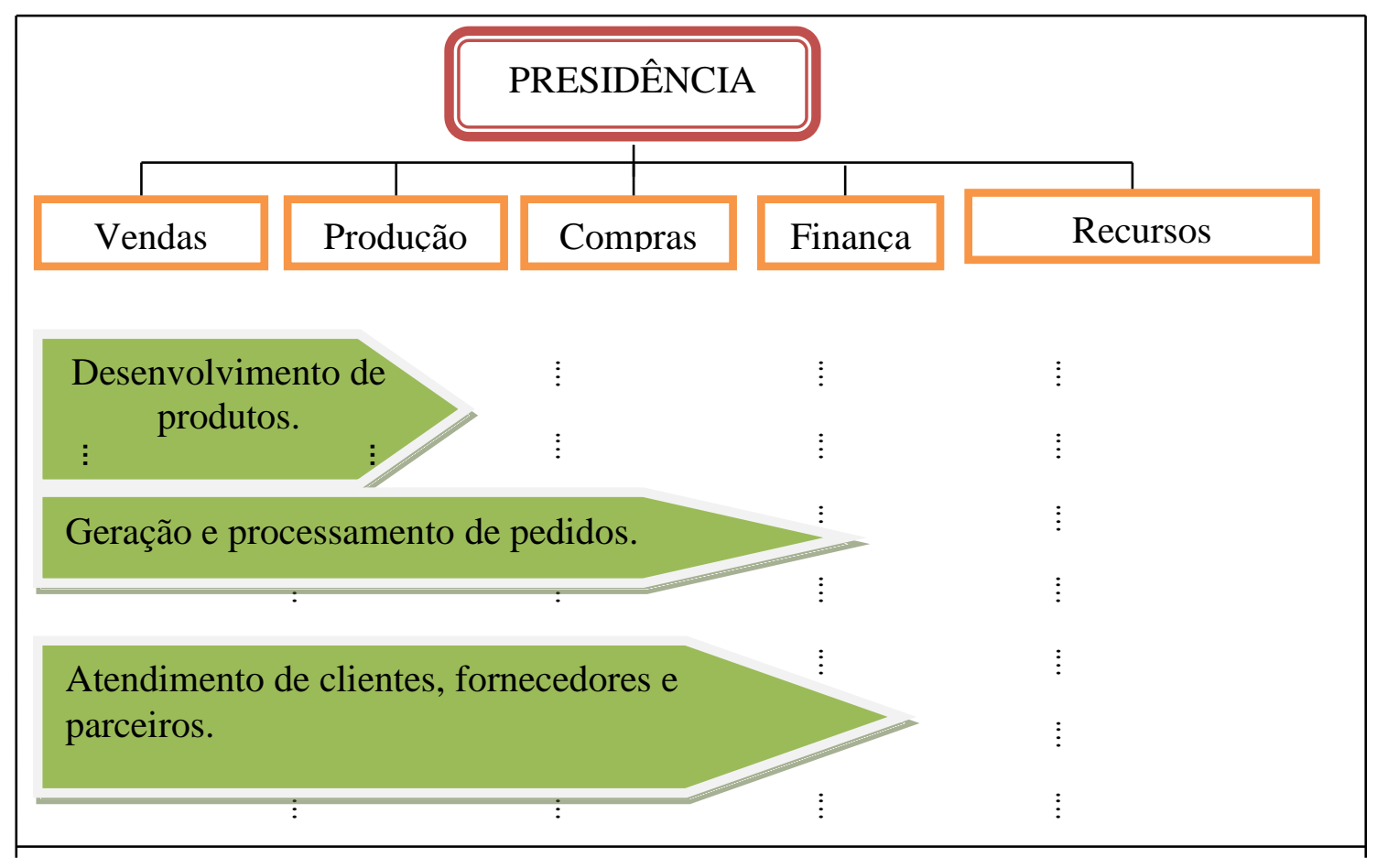

Figura 2: Processos rompem fronteiras departamentais Fonte: Adaptado de Maximiano (2012, p.329). 
Os Impactos da Reengenharia no processo de compensação de cheques: Estudo em uma Instituição Financeira João Marinho de Oliveira Filho, Rosângela Venâncio Nunes, Charles Washington Costa de Assis, Rita de Cássia Fonseca

Maximiano (2012) explica que com a interação dos setores pode haver contribuições entre ambos, por exemplo, um setor verificar ou deparar inconsistências do outro. A figura também pode representar o nível de responsabilidade dos respectivos setores no andamento do processo.

O alinhamento entre missão, avaliação de desempenho e tecnologia parece ser uma importante saída para as diversas ociosidades encontradas nos processamentos internos.

Para Maximiano (2012, p.332),

a gestão de processos foi potencializada pela tecnologia da informação, embora as duas ideias sejam independentes, mas a tecnologia da informação é uma ferramenta que facilita a BPM, por combinações entre software e hardware, gerando rapidez na informação e facilitando na tomada de decisão.

\subsection{Reengenharia de processos e suas aplicações}

Recentemente as constantes mudanças no meio externo empresarial fizeram com que as organizações repensassem a forma de como executar suas atribuições, com o propósito de atender as exigências do mercado. Para isso, deve sempre existir um estudo a fim de identificar as ações dos concorrentes e as necessidades dos clientes ou até mesmo saber o que faz a diferença. Para buscar esse diferencial no negócio, em muitos casos é preciso delinear e executar uma "reengenharia" (Business Process Re-engineering - BPR), cujo propósito é refazer algo que está sendo praticado de maneira sistemática e que venha a trazer benefícios que afetem diretamente a atividade-fim do negócio ou cliente, com intento de gerar diferenciação ao público alvo.

Hammer e Champy (1993 apud CHIAVENATO, 1994) entendem que a reengenharia é o repensar fundamental e a reestruturação radical dos processos empresariais, visando alcançar drásticas melhorias em indicadores críticos e contemporâneos de desempenho. Citam que a aplicação do modelo adequado impacta diretamente nos resultados relacionados ao custo, à qualidade, à velocidade $e$ ao atendimento. Segundo Morris e Brandon (1994 apud ARAÚJO, 2011), reengenharia é o 
Os Impactos da Reengenharia no processo de compensação de cheques: Estudo em uma

Instituição Financeira João Marinho de Oliveira Filho, Rosângela Venâncio Nunes, Charles Washington Costa de Assis, Rita de Cássia Fonseca

reprojeto dos processos de trabalho do negócio e a implantação de novos projetos. Os autores explanam alguns requisitos para que a reengenharia seja bem sucedida, conforme consta no Quadro 1.

\begin{tabular}{|c|c|}
\hline Requisito & Razão do requisito \\
\hline $\begin{array}{c}\text { A empresa deve ter capacidade de conduzir a reengenharia de } \\
\text { acordo com uma metodologia compreensiva e sistemática. }\end{array}$ & $\begin{array}{c}\text { Para que todos os envolvidos } \\
\text { possam compreender a } \\
\text { finalidade. }\end{array}$ \\
\hline $\begin{array}{c}\text { A administração da mudança deve ser coordenada } \\
\text { por todas as áreas da empresa que são por ela afetadas. }\end{array}$ & $\begin{array}{c}\text { O conjunto de departamentos } \\
\text { participantes toca o projeto. }\end{array}$ \\
\hline $\begin{array}{c}\text { A empresa deve ter capacidade de assessorar, planejar } \\
\text { e implementar a mudança em uma base contínua e constante. }\end{array}$ & $\begin{array}{c}\text { Ter visão sistêmica e de longo } \\
\text { prazo no processo da mudança. }\end{array}$ \\
\hline $\begin{array}{c}\text { A empresa deve ter capacidade para analisar } \\
\text { o impacto total das mudanças propostas. }\end{array}$ & $\begin{array}{c}\text { Controle sobre } \\
\text { os resultados obtidos. }\end{array}$ \\
\hline $\begin{array}{c}\text { A empresa deve ter capacidade de modelar } \\
\text { e simular as mudanças propostas. }\end{array}$ & $\begin{array}{c}\text { Usar a flexibilidade } \\
\text { quando necessário. }\end{array}$ \\
\hline $\begin{array}{c}\text { A empresa deve ter capacidade de usar esses modelos } \\
\text { em uma base contínua e constante. }\end{array}$ & $\begin{array}{c}\text { Transformar uma mudança do } \\
\text { presente para um projeto em } \\
\text { longo prazo. }\end{array}$ \\
\hline $\begin{array}{c}\text { A empresa deve ter capacidade de associar, uns com os outros, } \\
\text { todos os parâmetros administrativos da empresa. }\end{array}$ & $\begin{array}{c}\text { Assim como há integração dos } \\
\text { setores, as vertentes de gestão } \\
\text { também devem interagir. }\end{array}$ \\
\hline
\end{tabular}

Quadro 1: Capacidade de gestão para a reengenharia

Fonte: Adaptado de Morris e Brandon (1994).

O quadro sugere requisitos fundamentais para implantação da reengenharia de processos em qualquer área da organização. Morris e Brandon (1994 apud ARAÚJO, 2011) afirmam que caso tais condições citadas não sejam internalizadas pela organização, causará enormes dificuldades de gestão na reengenharia, minimizando ou até acabando com seus benefícios. Davenport (1994 apud ARAÚJO, 2011) afirma que a reengenharia busca as iniciativas de mudança radical do processo. O autor considera 
Os Impactos da Reengenharia no processo de compensação de cheques: Estudo em uma

Instituição Financeira

João Marinho de Oliveira Filho, Rosângela Venâncio Nunes, Charles Washington Costa de Assis, Rita de

Cássia Fonseca

que as mudanças devem ser drásticas, pois as necessidades são novas, fato este que exige novos processos.

BPR é uma tecnologia válida de trabalho para gerentes, consultores e profissionais de administração em geral, na medida em que seus pressupostos alertam a organização quanto à essencialidade de uma abordagem racional e analítica sobre a verdadeira unidade capaz de agregar valor real para o cliente: o processo de trabalho (ARAÚJO, 2011, p.258).

Nadler (1994) defende que para reprojetar um trabalho é necessário primeiro conhecer as exigências ambientais (demandas e oportunidades), para depois integrar pessoas e tecnologias.

$\mathrm{Na}$ maioria das abordagens sobre reengenharia, remete-se também a uma ferramenta bastante utilizada, o benchmarking, que é a busca por modelos aplicados por organizações que se destacam no mercado. Estudá-los e compará-los pode ser a porta inicial para as reformulações desejadas. De acordo com Spendolini (1999 apud ARAÚJO, 2011), há três tipos de benchmarking: o interno, que é a análise de atividades similares ou de departamentos internos que se destaquem por sua eficiência; 0 competitivo, que se baseia na análise dos processos dos concorrentes, a fim de se equiparar diante dos seus clientes; e o funcional, um estudo macro, que busca modelos de empresas referenciais em outros nichos, como outros setores, estados e países.

Corrêa e Corrêa (2011) citam que BPR é o redesenho radical dos processos, visando à obtenção de resultados mais drásticos e rápidos. Ressaltam, todavia, o alto risco que a empresa corre neste processo. Para Chiavenato (1994), a reengenharia de processos visa não a melhoria dos processos, mas sim a substituição por processos inteiramente novos, de modo radical e revolucionário. O autor ainda destaca o contraste entre melhoria contínua da qualidade e a reengenharia, que não busca só melhorar o processo, mas sim reinventá-lo, como forma de satisfazer as necessidades e expectativas de clientes externos e internos da organização, com objetivos específicos 
Os Impactos da Reengenharia no processo de compensação de cheques: Estudo em uma Instituição Financeira João Marinho de Oliveira Filho, Rosângela Venâncio Nunes, Charles Washington Costa de Assis, Rita de Cássia Fonseca

quanto ao desempenho, a fim de assegurar vantagem competitiva e o máximo de retorno do investimento.

Slack et al. (2002) concordam com os demais autores que a reengenharia revoluciona radicalmente os modelos em questão e ainda justifica que o tema é uma mistura de ideias que surgiram a partir dos anos 1990, como por exemplo: just in time, os fluxogramas de processos, o exame crítico no estudo de método, o gerenciamento de redes e operações focadas no consumidor. Todavia, de maneira sistêmica os autores expõem controvérsias sobre o assunto, citando que

[...] pela própria natureza, a BPR preocupa-se somente com as atividades de trabalho em vez de preocupar-se com as pessoas que desempenham as tarefas [...] é imprecisa como abordagem, seus componentes não podem chegar a um acordo se ela deve ser radical ou pode ser implementada gradualmente [...] deve ou não ser apoiada por tecnologia da informação [...] é tratada por alguns gerentes como a última palavra na gestão, a cura para todos os males [...] é meramente uma desculpa para dispensar funcionários , empresas que querem fazer downsizing, usam BPR como desculpa para reduzir seus quadro de líderes e colaboradores[...] uma combinação de redesing radical junto com downsizing pode significar a perda da experiência vital da produção, deixando vulnerável a qualquer turbulência mais séria, uma vez que ela já não teria conhecimento e experiência para lidar com mudanças inesperadas (SLACK et al., 2002, p.607).

O presente estudo acompanha a ideia de que redefinir processos para buscar melhorias drásticas e obter diferenciais competitivos pode gerar valor ao processo de compensação de cheques em uma instituição financeira, pois possibilita atender as necessidades e expectativas de clientes externos e internos da organização. Apesar do tema estar presente em vários dilemas organizacionais, ainda assim se percebe que o objetivo maior da reengenharia é a proposta de redesenhar a empresa a partir de seus processos, buscando agilidade, redução de desperdícios e satisfação a quem detém os anseios. 
Os Impactos da Reengenharia no processo de compensação de cheques: Estudo em uma Instituição Financeira João Marinho de Oliveira Filho, Rosângela Venâncio Nunes, Charles Washington Costa de Assis, Rita de Cássia Fonseca

Após argumentos tão pertinentes de ambas as partes, conclui-se que a aplicação da reengenharia é de uma enorme complexidade para a organização e deve ser implementada com o máximo de visão sistêmica por parte da equipe responsável pela reestruturação das atividades ou dos processos, uma vez que falhas foram detectadas e até mesmo deficiências nos indicadores de desempenho.

\subsection{Avaliação de Desempenho}

O mundo das organizações passa por diversos dilemas voltados aos seus clientes, que buscam constantemente produtos e serviços que atendam suas expectativas em diferentes aspectos. Assim sendo, as empresas devem avaliar 0 desempenho em diversas etapas do processamento de sua atividade final. Com o propósito de atender às tais expectativas, uma ferramenta bastante utilizada atualmente é a avaliação de desempenho através da definição de metas que podem ser acompanhadas por meio de indicadores.

Para Maximiano (2012, p.233), o desempenho da organização pode ser medido por meio de indicadores, podendo ser segmentado de acordo com as áreas funcionais e com foco nos pontos fracos. $O$ autor acredita que os objetivos devem ser expressos em termos numéricos, associados a indicadores específicos de desempenho.

Segundo Orofino (2009), um sistema de medida é composto por indicadores e suas metas. O Gráfico 1 um mostra e diferencia indicador de meta. 
Os Impactos da Reengenharia no processo de compensação de cheques: Estudo em uma

Instituição Financeira

João Marinho de Oliveira Filho, Rosângela Venâncio Nunes, Charles Washington Costa de Assis, Rita de

Cássia Fonseca

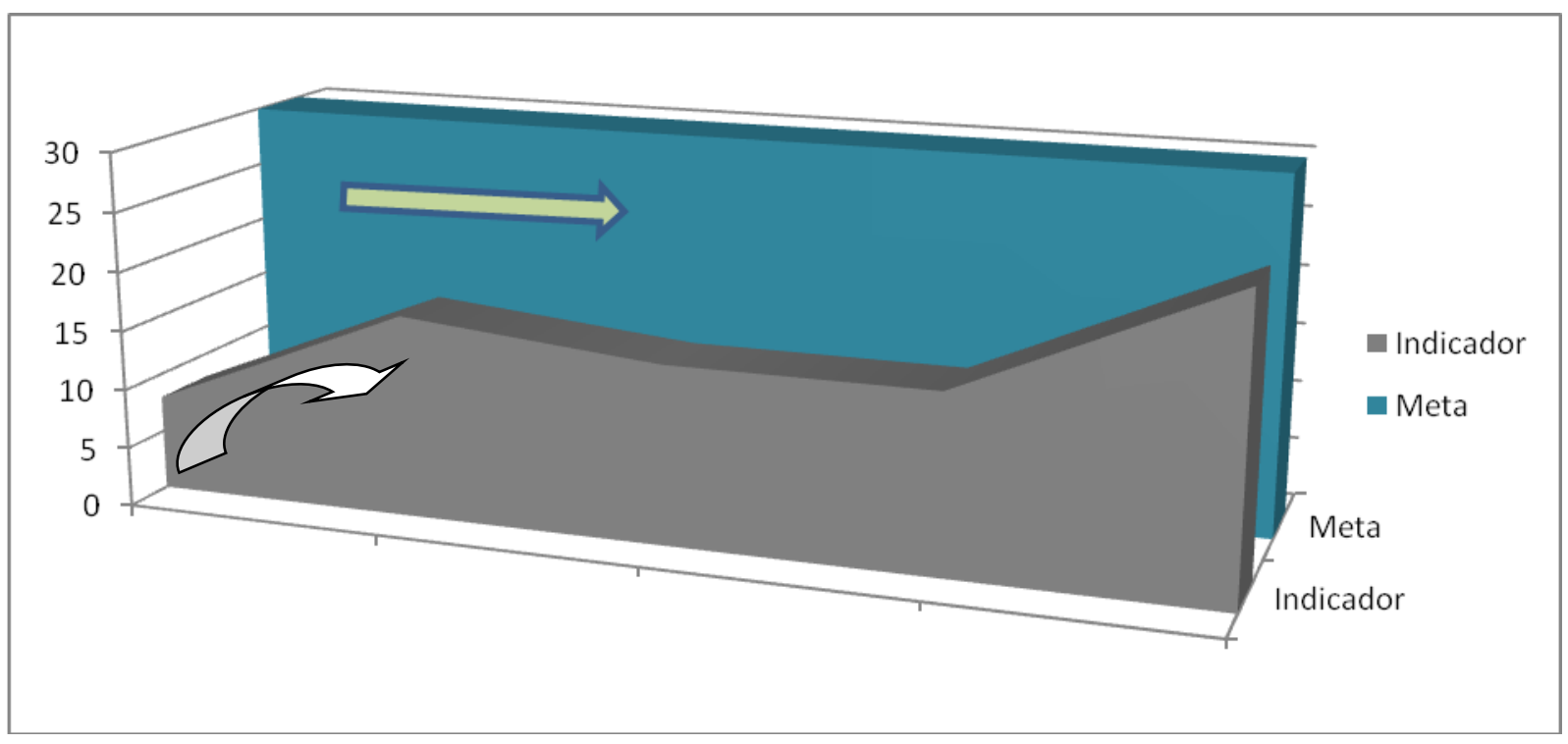

Gráfico 1: Meta x Indicador

Fonte: Adaptado de Orofino (2009).

O autor destaca no gráfico que os indicadores servem para mostrar o quanto o rendimento, por exemplo, está próximo da meta. Portanto, é uma ferramenta que permite o controle direto das atividades, possibilitando ações imediatas.

Já para Sordi (2005, p.50),

indicadores de desempenho vinculam-se à gestão de processos através da medição de apontadores que mostram a eficiência do processo, são exemplos: conversão de entradas em saídas; quantidade processada de matérias em um determinado tempo; econômicos e financeiros (custo, faturamento gerado, lucratividade, retorno gerado, ativos empregados); os de produtividade e qualidade (erros e defeitos gerados, tempo de reconfiguração de produto, satisfação dos clientes); os sociais e ambientais (profissionais alocados no processo); os de aprendizado e conhecimento (evolução do banco de ideias, recebimento de sugestões, aplicação pratica das sugestões).

O autor ainda afirma que um dos desafios das organizações orientadas aos processos é ter indicadores de desempenho eficientes, que tornem as empresas aptas 
Os Impactos da Reengenharia no processo de compensação de cheques: Estudo em uma Instituição Financeira João Marinho de Oliveira Filho, Rosângela Venâncio Nunes, Charles Washington Costa de Assis, Rita de Cássia Fonseca

a perceber com rapidez as condições que estão começando a afetar seus processos de negócio e a organização.

De acordo com Corrêa e Corrêa (2011), há duas formas de se atingir objetivos. A Figura 3 mostra as diferenças entre eficiência, que mede quão economicamente os recursos foram utilizados para atingir os objetivos, e eficácia, que apenas atinge os objetivos relacionados aos atores fins.

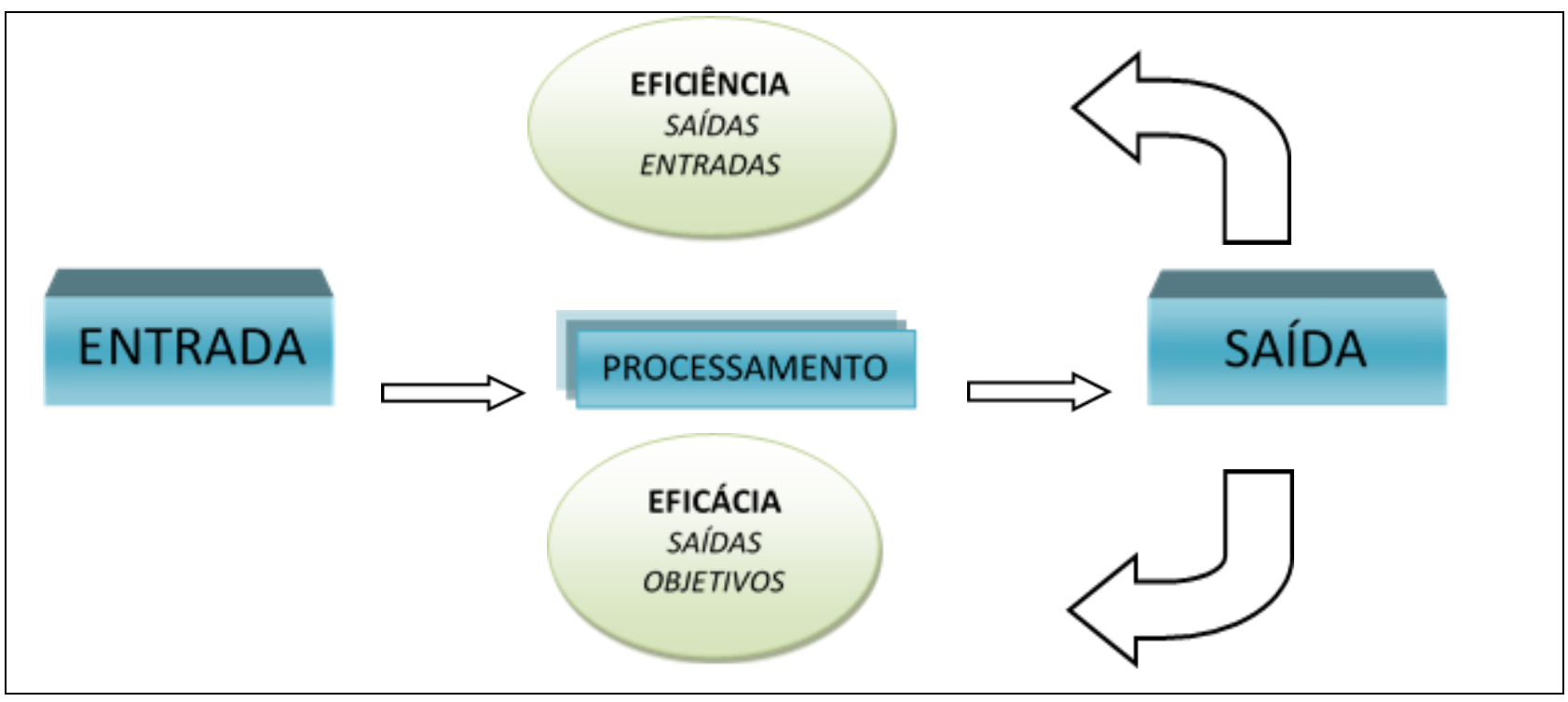

Figura 3: Diferença entre eficiência e eficácia.

Fonte: Adaptado de Corrêa e Corrêa (2011, p.159).

A Figura 3 diferencia a eficiência da eficácia: enquanto uma atinge objetivos utilizando de forma correta os recursos, a outra apenas atinge objetivos sem verificar a utilização dos recursos. Para os autores, um sistema de medição de desempenho pode ser definido como um conjunto coerente de métricas usado para quantificar eficiência e eficácia.

Outra ferramenta conhecida é o Balanced Scorecard - BSC, idealizada por Kaplan e Norton (1997). Os autores mencionam que se trata de um instrumento de avaliação balanceada que se destina à medição de elementos que agregam à visão 
Os Impactos da Reengenharia no processo de compensação de cheques: Estudo em uma Instituição Financeira João Marinho de Oliveira Filho, Rosângela Venâncio Nunes, Charles Washington Costa de Assis, Rita de Cássia Fonseca

estratégica da organização, como: clientes, financeira, aprendizado e crescimento e processos internos.

O Quadro 2 resume os segmentos e seus respectivos aspectos para mensuração no cotidiano organizacional.

\begin{tabular}{|c|c|}
\hline \multicolumn{2}{|r|}{ BSC - Balanced Scorecard } \\
\hline Perspectivas & Aspectos mensuráveis \\
\hline Financeira & $\begin{array}{l}\text { Liquidez; crescimento da receita; margem bruta; vendas; custo unitário do } \\
\text { produto; geração de caixa. }\end{array}$ \\
\hline Consumidor & $\begin{array}{l}\text { Número de atendimentos; números de reclamações } \\
\text { ou sugestões; participação no mercado; } \\
\text { número de novos clientes. }\end{array}$ \\
\hline $\begin{array}{l}\text { Processos } \\
\text { Críticos }\end{array}$ & $\begin{array}{l}\text { Conformidade do produto/ serviço em relação ao padrão; } \\
\text { número de inconsistências; número de retrabalho; } \\
\text { eficiência operacional. }\end{array}$ \\
\hline $\begin{array}{l}\text { Aprendizado e } \\
\text { Crescimento }\end{array}$ & $\begin{array}{l}\text { Tempo recuperação de investimento; capacidade de inovar; } \\
\text { receita de novos produtos ou serviços }\end{array}$ \\
\hline $\begin{array}{l}\text { Responsabilidade } \\
\text { Social }\end{array}$ & $\begin{array}{l}\text { Conformidade social; imagem pública; conformidade ambiental. } \\
\text { benefícios dos processos; custo ambiental; }\end{array}$ \\
\hline Pessoas & $\begin{array}{l}\text { Retenção de pessoas-chave; satisfação; competência; eficácia dos treinadores; } \\
\text { equidade de remuneração; segurança e participação; }\end{array}$ \\
\hline $\begin{array}{l}\text { Aquisição e } \\
\text { Fornecedores }\end{array}$ & $\begin{array}{l}\text { Qualidade dos produtos; produtividade de aquisição; } \\
\text { garantia e relacionamento. }\end{array}$ \\
\hline $\begin{array}{l}\text { Ambiente } \\
\text { Organizacional }\end{array}$ & Capital intelectual; qualidade do sistema de informação. \\
\hline
\end{tabular}

Quadro 2: Perspectivas de abordagens do BSC (Balanced Scorecard) Fonte: Adaptado de Kaplan e Norton (1997).

A ferramenta do BSC segmenta os aspectos mensuráveis em oito grupos de análises, conforme evidencia o quadro anterior. Portanto, cada segmento deve ter definido seus aspectos mensuráveis, a fim de facilitar a medição e o gerenciamento dos indicadores.

Já Slack et al. (2002, p.70) contextualizam a avaliação de desempenho em relação aos objetivos da produção, adotando indicadores para diversos segmentos e 
Os Impactos da Reengenharia no processo de compensação de cheques: Estudo em uma Instituição Financeira João Marinho de Oliveira Filho, Rosângela Venâncio Nunes, Charles Washington Costa de Assis, Rita de Cássia Fonseca

também a designação de seus responsáveis pelo controle e monitoramento do desempenho voltado à produção. Os autores segmentam os indicadores em cinco objetivos de desempenho, como mostra o quadro a seguir.

\begin{tabular}{|c|c|}
\hline Objetivo de desempenho & Algumas medidas típicas \\
\hline Qualidade & $\begin{array}{l}\text { Número de defeitos por unidade } \\
\text { Nível de reclamação do consumidor } \\
\text { Nível de refugo } \\
\text { Alegações de garantia } \\
\text { Tempo médio entre falhas } \\
\text { Escore de satisfação do consumidor }\end{array}$ \\
\hline Velocidade & $\begin{array}{c}\text { Tempo de cotação do consumidor } \\
\text { Lead time de pedido } \\
\text { Frequência de entregas } \\
\text { Tempo de atravessamento real versus teórico } \\
\text { Tempo de ciclo }\end{array}$ \\
\hline Confiabilidade & $\begin{array}{c}\text { Porcentagem de pedidos entregue com atraso } \\
\text { Atraso médio de pedidos } \\
\text { Proporção de produtos em estoque } \\
\text { Desvio-médio de promessa de chegada } \\
\text { Aderência à programação }\end{array}$ \\
\hline Flexibilidade & $\begin{array}{c}\text { Tempo necessário para desenvolver } \\
\text { novos produtos/ serviços } \\
\text { Faixa de produtos ou serviços } \\
\text { Tempo de mudança de máquina } \\
\text { Tamanho médio de lote } \\
\text { Tempo para aumentar a taxa de atividade } \\
\text { Capacidade média/ Capacidade máxima } \\
\text { Tempo para mudar programações }\end{array}$ \\
\hline Custo & $\begin{array}{c}\text { Tempo mínimo de entrega/ tempo médio de entrega } \\
\text { Variação contra orçamento } \\
\text { Utilização dos recursos } \\
\text { Produtividade da mão de obra } \\
\text { Valor agregado } \\
\text { Eficiência } \\
\text { Custo por hora de operação }\end{array}$ \\
\hline
\end{tabular}

Quadro 3: Medidas parciais de desempenho típicas

Fonte: Slack et al. (2002). 
Os Impactos da Reengenharia no processo de compensação de cheques: Estudo em uma Instituição Financeira João Marinho de Oliveira Filho, Rosângela Venâncio Nunes, Charles Washington Costa de Assis, Rita de Cássia Fonseca

O quadro expõe a divisão dos aspectos mensuráveis em seus respectivos objetivos de desempenho, ou seja, distribui medidas típicas entre qualidade, velocidade, confiabilidade, flexibilidade, custo.

Apesar dos autores utilizarem uma abordagem voltada à produção, este trabalho acompanha algumas características de tal estrutura quanto à classificação dos objetivos de desempenho, uma vez que serão aplicados no processo de reengenharia numa instituição financeira.

\subsection{Os impactos da reengenharia na avaliação de desempenho}

Nas organizações modernas, percebe-se que qualquer mudança deve passar por sérias avaliações, entretanto, tais mensurações já devem estar alinhadas ao determinado processo em questão. Com a implementação da reengenharia fica mais fácil medir, comparar e diagnosticar velhos e novos problemas.

Oliveira (2008, p. 292) cita que a avaliação possui vários atores, dentre eles destacam-se

os decisores (aqueles que possuem a legitimidade para decidir); os envolvidos (aqueles que estão submetidos às consequências da avaliação, mesmo sem dela participar); e os analistas (consultores externos que orientam a avaliação, a pedido dos decisores ou dos envolvidos).

Como já foi citado anteriormente, a reengenharia é uma das ferramentas que possibilita realizar mudanças organizacionais, sendo ainda capaz de gerar melhoramento no processo e, consequentemente, no desempenho, uma vez que estes estejam claramente definidos e coerentes.

De acordo com Slack et al. (2002, p.590), 
Os Impactos da Reengenharia no processo de compensação de cheques: Estudo em uma Instituição Financeira João Marinho de Oliveira Filho, Rosângela Venâncio Nunes, Charles Washington Costa de Assis, Rita de Cássia Fonseca

antes que os gerentes possam idealizar sua abordagem para o melhoramento de suas operações, eles precisam saber o quanto ela já é boa. A urgência, direção e prioridades de melhoramento serão determinadas parcialmente em razão de o atual desempenho de uma operação ser julgado como bom, ruim ou indiferente. Todas as operações produtivas, portanto, precisam de alguma forma de medida de desempenho, com pré-requisito para o melhoramento.

Os autores esclarecem que não basta só executar a reengenharia, mas sim avaliar todo o desempenho ocasionado antes de qualquer melhoria; os gerentes devem tomar uma medida cautelosa e coerente. Portanto, torna-se notória a importância das organizações definirem seus elementos mensuráveis, pois os impactos originados por qualquer reengenharia podem ser facilmente comparados, com o propósito de mostrar o quanto é relevante transformar processos empresariais, principalmente aqueles que podem agregar valor aos clientes.

\subsection{Processo de compensação de cheques no Brasil}

O processo de compensação de cheques no Brasil se dá através da integração entre sistemas, grupos e instituições financeiras (IF's) que são citados (as) no decorrer deste tópico, com o objetivo de estabelecer o perfeito funcionamento do sistema de compensação no país, assegurando o atendimento aos objetivos comuns, buscando a estabilidade das operações como forma de resguardar todos os participantes e clientes do Sistema Financeiro Nacional (SFN).

Para se compreender o termo compensação de cheques (COMPE), é preciso associá-lo à palavra liquidação, em que clientes emitem cheques a fim de efetuarem pagamentos e beneficiários recebem créditos em suas respectivas contas. Basicamente, a compensação é responsável por toda movimentação de arquivos e documentos em prol da liquidação das ordens de pagamento geradas por correntistas das instituições financeiras.

De acordo com Costa (2003), a palavra compensação é originaria do latim cumpensatio-onis, que significa pender, contrabalançar ou equilibrar. Efetivamente, os 
Os Impactos da Reengenharia no processo de compensação de cheques: Estudo em uma Instituição Financeira João Marinho de Oliveira Filho, Rosângela Venâncio Nunes, Charles Washington Costa de Assis, Rita de Cássia Fonseca

registros indicam que a primeira câmara de compensação foi idealizada na Inglaterra em 1773, pela necessidade de trocas e cobranças entre os bancos emissores de cheques, ou seja, tendo que haver encontros diários para viabilizar as transações internas e externas às instituições.

Costa (2003, p. 10), define o serviço de compensação de cheques e outros papéis como

\begin{abstract}
um serviço de caráter público que permite a liquidação das transações interbancárias ou de transferência de fundos, resultante da atividade econômica de uma Instituição Financeira promovendo a diferença entre débitos e créditos de responsabilidade de cada uma das instituições financeiras envolvidas.
\end{abstract}

No Brasil, as primeiras tentativas de funcionamento da COMPE aconteceram nos anos de 1890 e 1919, no entanto, sem êxito. Todavia, em 1921 o Banco do Brasil (BB), como instituição já consolidada e pertencente unicamente ao governo, toma a iniciativa e cria e administra a primeira câmara de compensação no Brasil (COMPE), que posteriormente passaria a se chamar câmara de compensação de cheques e outros papéis.

Após 30 anos de sua criação, o BB já contava com o apoio de 15 departamentos de COMPE espalhados pelo país, buscando atender as áreas que necessitavam da prestação desse serviço, uma vez que cada vez mais o cheque se tornava uma ordem de pagamento à vista e trazia comodidade para os correntistas.

A partir de 1964, com o surgimento do Banco Central do Brasil (BACEN), a regulamentação passa a ser do órgão majoritário do SFN, cabendo ao BB apenas executar os serviços de compensação de cheques, regulados pelas normas do Banco Central.

O processamento se manteve estável, mas a utilização do cheque era cada vez mais crescente. Portanto, a partir da década de 1980 órgãos que compunham o SFN criaram grupos de estudos de compensação e grupos de avaliações, com a finalidade 
Os Impactos da Reengenharia no processo de compensação de cheques: Estudo em uma Instituição Financeira João Marinho de Oliveira Filho, Rosângela Venâncio Nunes, Charles Washington Costa de Assis, Rita de Cássia Fonseca

de buscar o perfeito funcionamento da COMPE e também de procurar formas de melhorias para o processo; o Grupo de Avaliação de Desempenho (GAD) e o Grupo de Estudos de Compensação, são exemplos.

Uma das medidas encontradas para facilitar o gerenciamento das liquidações em todo país foi a criação do Sistema Integrado Regional de Compensação (SIRC), com o propósito de encurtar distâncias entre as agências e as centralizadoras, pois os documentos levavam dias para serem compensados e devolvidos, por motivos de transporte e de não integração dos participantes. A Figura 4 resume todo o contexto que foi exposto até agora, ressaltando que nos últimos anos, mais precisamente até 2011, este foi o modelo utilizado para o processamento de compensação dos cheques no Brasil.

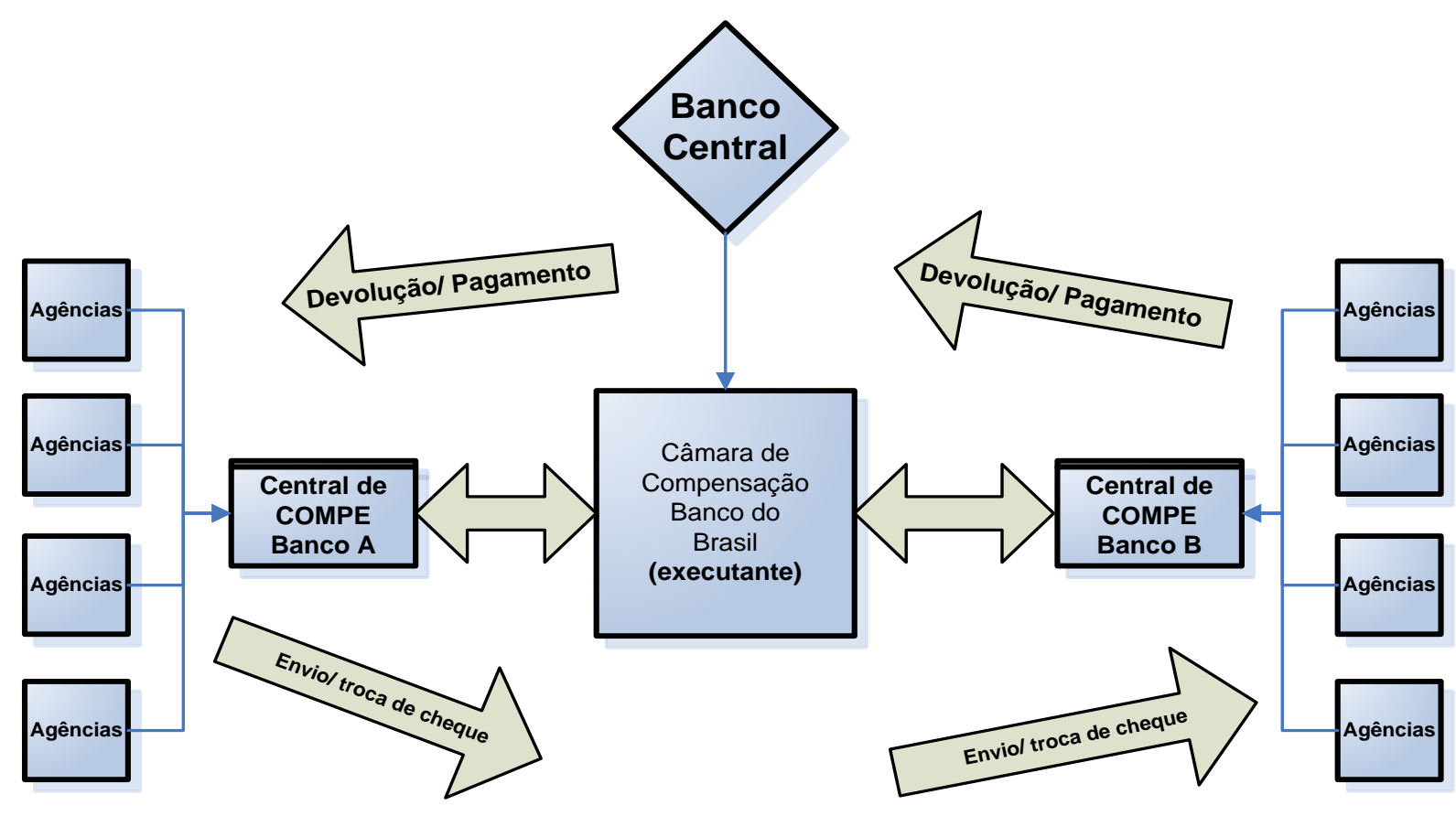

Figura 4: Fluxo macro de compensação de cheques no Brasil Fonte: FEBRABAN (2011). 
Os Impactos da Reengenharia no processo de compensação de cheques: Estudo em uma Instituição Financeira João Marinho de Oliveira Filho, Rosângela Venâncio Nunes, Charles Washington Costa de Assis, Rita de Cássia Fonseca

A figura resume como ocorria a movimentação dos documentos até o ano de 2011, antes da implementação da Compe por imagem. O processo se inicia na parte inferior esquerda da figura, quando as agências bancárias recebiam os cheques de seus respectivos depositantes, capturavam os dados do cheque, enviavam os documentos e os dados à centralizadora do Banco do Brasil, que repassava as informações ao banco pagador, ou sacado. Após o trânsito destas informações, o fluxo já ocorre na parte superior direita, quando o banco sacado enviava a resposta do pagamento ou não dos cheques apresentados, cabendo ao BB mediar tais movimentações para informar o lançamento de débitos e créditos, ou informar o motivo de devolução ao banco do depositante.

Com a crescente movimentação de documentos e as complexidades logísticas do país, foi proposto pelo executante (BB) ferramentas que facilitassem o manuseio dos cheques durante seu processamento. Portanto, em 1985, foi criada a "COMPE ELETRÔNICA", que já contava com a padronização dos cheques e o incremento da banda magnética nos documentos. Possibilitava a captura dos dados eletrônicos dos cheques, antes que fossem enviados à centralizadora, a qual passou a receber os dados lógicos (banda magnética, valor, data de movimentação contábil) junto aos documentos físicos, via on-line e transporte, respectivamente, sendo mais viável o manuseio, pois as agências já poderiam colaborar com uma parte das atividades.

As agências capturavam os dados da banda através de leitores magnéticos, que normalmente eram utilizados nos caixas, assim elas não dependiam mais do transporte de malotes para dar início ao processamento, ou seja, com a captura eletrônica dos dados, as agências já poderiam disponibilizar os dados aos seus respectivos centros de compensação. Enquanto isso, nas centralizadoras, já era possível dar início ao processo de troca de informações entre banco sacado e banco depositante, progredindo a primeira parte dos serviços necessários para que o cliente beneficiário soubesse quando seria liberado seu crédito. A Figura 5 traz a imagem de um cheque contendo a banda magnética. 
Os Impactos da Reengenharia no processo de compensação de cheques: Estudo em uma Instituição Financeira João Marinho de Oliveira Filho, Rosângela Venâncio Nunes, Charles Washington Costa de Assis, Rita de Cássia Fonseca

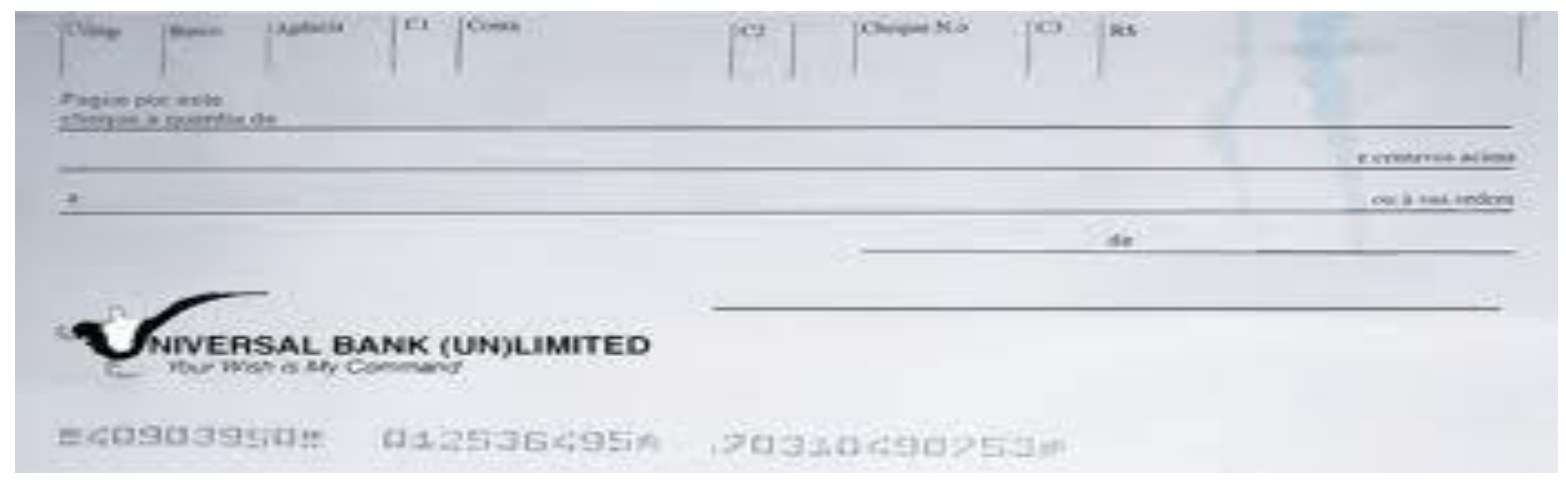

Figura 5: Cheque com banda magnética

Fonte: www.osegredo.tv. (2013).

A figura mostra em seu canto inferior a banda magnética do documento, composta por três campos de caracteres. Cada campo traz as informações necessárias sobre a origem do cheque.

A COMPE eletrônica veio apenas como uma das formas de agilizar o processo e viabilizar o cumprimento ou redução de prazos aos clientes, processo que após décadas passara por reengenharia, como a COMPE POR IMAGEM ou "truncagem". Atualmente, o sistema conta com 15 câmaras de compensação de cheques em todo país. O quadro abaixo mostra os centros e seus respectivos nomes.

\begin{tabular}{|l|l|l|}
\hline \multicolumn{4}{|c|}{ Câmaras de compensação (código + nome) } \\
\hline 001 RIO DE JANEIRO & 008 FORTALEZA & 021 VITÓRIA \\
\hline 002 MANAUS & 009 CURITIBA & 033 BELO HORIZONTE \\
\hline 003 BELÉM & 010 PORTO ALEGRE & 048 CAMPO GRANDE \\
\hline 006 SALVADOR & 016 FLORIANÓPOLIS & 086 GOIÂNIA \\
\hline 007 RECIFE & 018 SÃO PAULO & 452 BRASÍLIA \\
\hline
\end{tabular}

Quadro 4: Câmaras de compensação no Brasil Fonte: FEBRABAN (2011).

Estas câmaras são responsáveis pelo processamento de cheques na sua respectiva circunscrição. Ressalta-se, ainda, que o executante centraliza e distribui todas as informações na cidade de São Paulo. 
Os Impactos da Reengenharia no processo de compensação de cheques: Estudo em uma Instituição Financeira João Marinho de Oliveira Filho, Rosângela Venâncio Nunes, Charles Washington Costa de Assis, Rita de Cássia Fonseca

A COMPE POR IMAGEM é mais um dos exemplos de reestruturação pelo qual passa o processo de compensação de cheques no Brasil. Foi colocada em discussão pela diretoria colegiada do BACEN em 2011, acabando por decidir, através de Circular no 3532, de 20 de abril de 2011, que era mais viável que as instituições acolhedoras de cheques retivessem os documentos e capturassem a imagem para fins de processamento, ou seja, o cheque não precisaria mais ser transportado para as centralizadoras, e sua imagem seria associada com outros softwares a fim de assegurar os prazos vigentes de processamento/ devolução, que são: um dia, a contar do dia posterior à data do depósito, para cheques com valor superior à $R \$ 299,99$ e dois dias, para valor inferior, a contar do dia posterior à data do depósito, fator esse que fez com que fosse mitigada uma enorme cadeia de recursos.

Portanto, percebe-se que as reestruturações podem impactar diretamente no desempenho em diversas áreas das instituições financeiras participantes de tal processo.

\section{METODOLOGIA}

Quanto ao método científico, é válido mencionar que o método dedutivo e o indutivo adéquam-se ao estudo. Para Silva e Menezes (2001, p. 26), o raciocínio dedutivo tem o objetivo de explicar o conteúdo das premissas, por intermédio de uma cadeia de raciocínio em ordem descendente, de análise do geral para o particular, chegando-se a uma conclusão.

Quanto ao objetivo trata-se de uma pesquisa descritiva, pois foram descritos fatos e dados do processo de compensação de cheques em uma instituição financeira, com o propósito de analisá-los e responder ao problema. Para Beuren (2006), a pesquisa descritiva é o meio termo entre a exploratória e a explicativa, ou seja, respectivamente, não é tão preliminar e nem tão aprofundada. A autora ainda afirma que os resultados obtidos podem contribuir na identificação das relações existentes entre variáveis 
Os Impactos da Reengenharia no processo de compensação de cheques: Estudo em uma Instituição Financeira João Marinho de Oliveira Filho, Rosângela Venâncio Nunes, Charles Washington Costa de Assis, Rita de Cássia Fonseca

estudadas. Desta forma, o estudo descreve alterações em processos e seus impactos gerados.

Do ponto de vista de sua natureza, o estudo segue a pesquisa aplicada, pois se busca conhecimento para aplicação no caso específico dos impactos da reengenharia de processos na compensação de cheques. Silva e Menezes (2001, p. 20) afirmam que a pesquisa aplicada objetiva gerar conhecimentos para aplicação prática dirigida à solução de problemas específicos, envolvendo verdades e interesses locais. Quanto à abordagem, pode-se associar o estudo com uma abordagem qualitativa e quantitativa, e quanto ao procedimento técnico trata-se de uma pesquisa documental complementada por entrevista.

\section{APRESENTAÇÃO E ANÁISE DOS DADOS}

\subsection{Ambiente de estudo}

O ambiente em estudo trata-se de uma câmara de compensação de cheques localizada em um dos centros regionais do executante, conforme evidencia o Quadro 3. Para preservar a entidade, seu nome não é mencionado.

O serviço de compensação de cheques é considerado um serviço essencial para o equilíbrio econômico do país. Dessa forma, cabe aos participantes estabelecer e dar suporte à uma estrutura que viabilize o cumprimento dos objetivos finais. $O$ setor de compensação de cheques dispõe da seguinte estrutura hierárquica. 
Os Impactos da Reengenharia no processo de compensação de cheques: Estudo em uma Instituição Financeira João Marinho de Oliveira Filho, Rosângela Venâncio Nunes, Charles Washington Costa de Assis, Rita de Cássia Fonseca

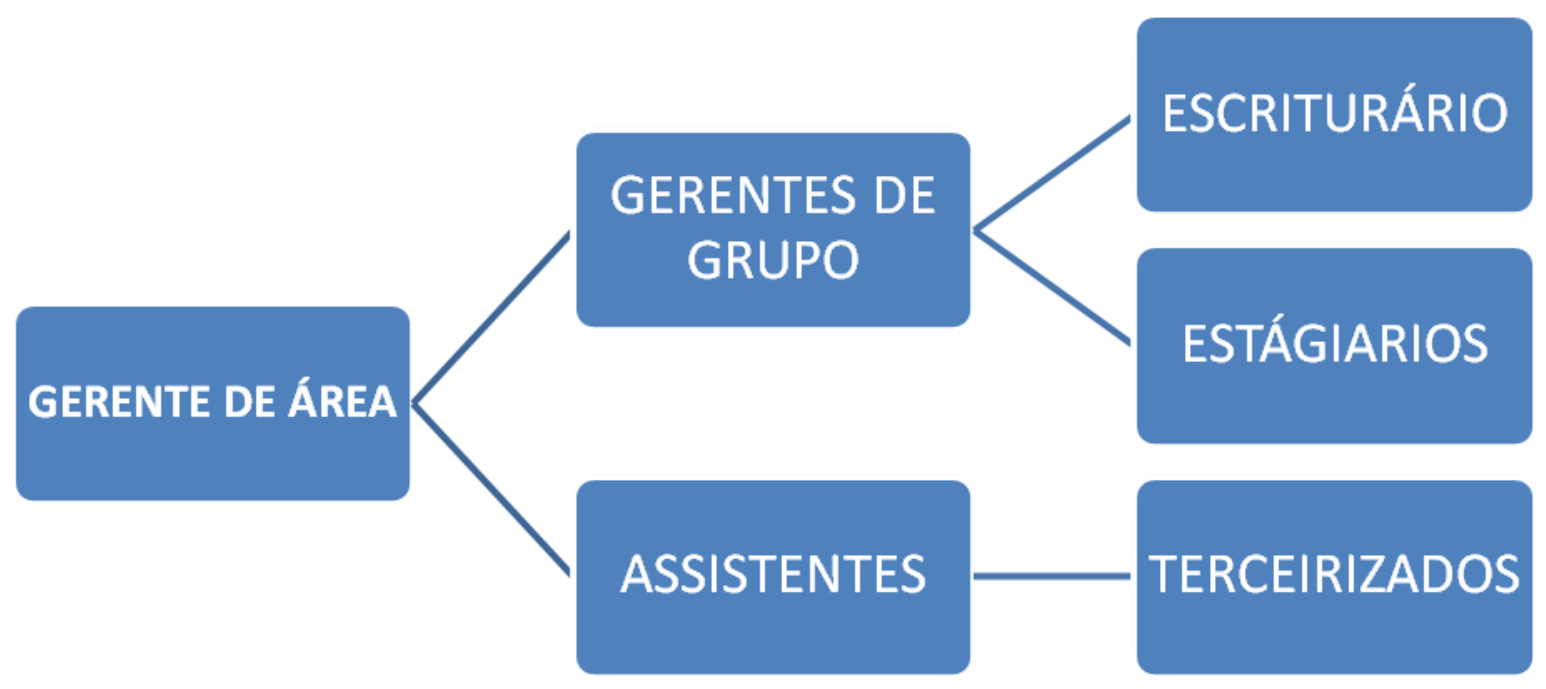

Figura 6: Cadeia Hierárquica do ambiente analisado

Fonte: Elaborado pelos autores com base em entrevista com gestor do núcleo.

O número de colaboradores não é citado, tendo em vista que na análise dos impactos da reengenharia tais dados são expostos.

Para um melhor entendimento do setor, a empresa divide suas atividades por regiões, para um total de 15 Compes, geridas por cinco Centros de Suporte Operacionais - CSO (Brasília, Belo Horizonte, Curitiba, São Paulo e Recife), no território nacional, localizadas em cidades estratégicas, as quais facilitam todo o trabalho logístico e de processamento das devidas obrigações.

\subsubsection{Processo antes da reengenharia}

Como já foi citado anteriormente, desde a implantação da COMPE eletrônica, até o ano de 2011, o processo se deu através da troca de informações e de documentos entre os participantes e o executante.

A Figura 7 mostra o fluxograma detalhando o processo e em seguida seu script referente ao funcionamento do sistema até a data de publicação da Carta circular do BACEN no 3532 em 2011. 
Os Impactos da Reengenharia no processo de compensação de cheques: Estudo em uma Instituição Financeira João Marinho de Oliveira Filho, Rosângela Venâncio Nunes, Charles Washington Costa de Assis, Rita de Cássia Fonseca

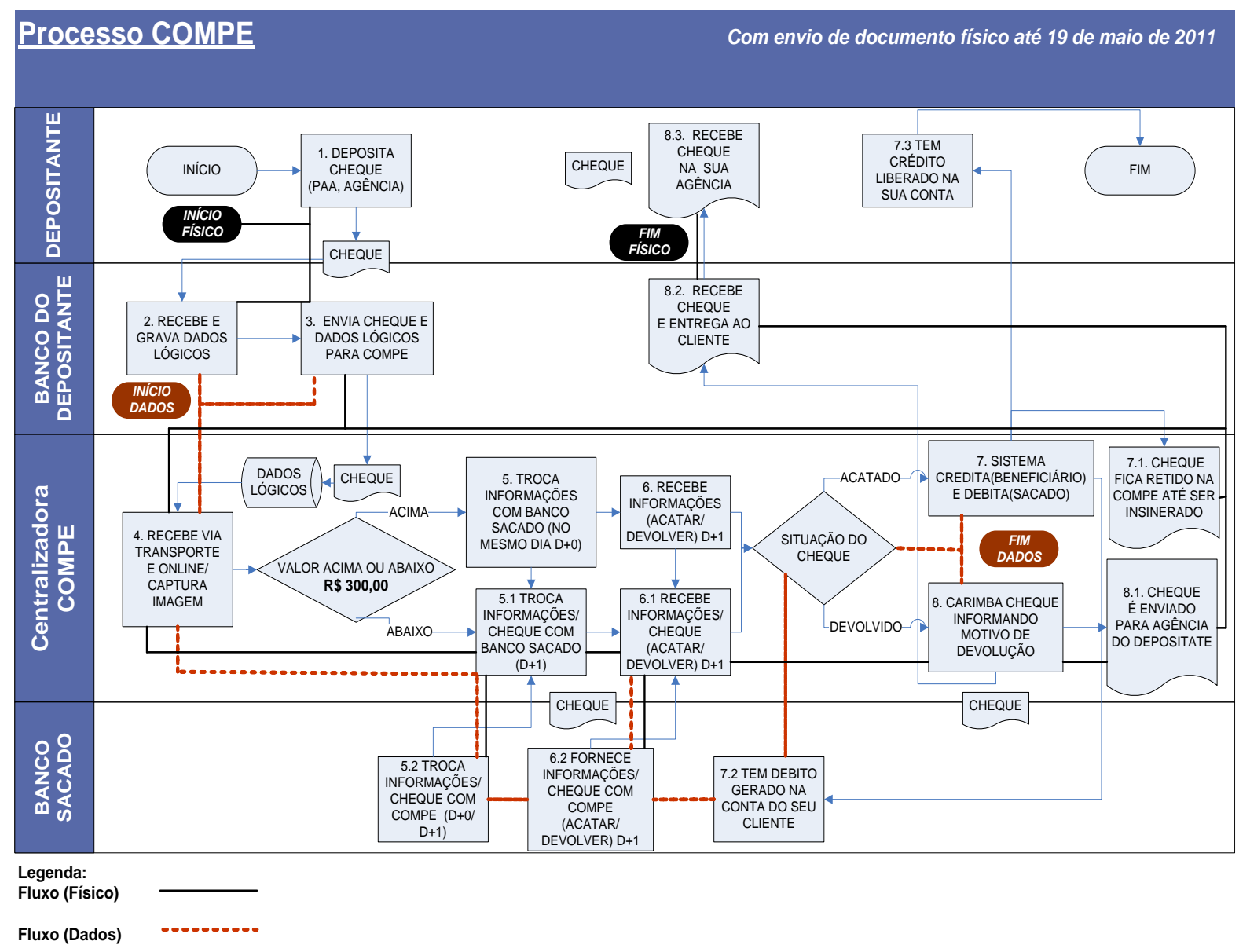

Figura 7: Fluxograma do processo de compensação de cheques antes da truncagem

Fonte: Elaborado pelos autores com base nas informações coletadas com os gestores.

\section{Script do processo antes da reengenharia:}

1. Beneficiário/ Depositante: Deposita/ apresenta o cheque na agência;

2. Banco Depositante: Recebe documento, grava dados lógicos através da banda magnética do mesmo;

3. Banco Depositante: Envia cheque e dados lógicos à centralizadora de compensação respectiva à sua praça;

4. Centralizadora Compe: Recebe o cheque via transporte (malote aéreo/ terrestre), os dados via on-line, e captura a imagem do cheque; 
Os Impactos da Reengenharia no processo de compensação de cheques: Estudo em uma Instituição Financeira João Marinho de Oliveira Filho, Rosângela Venâncio Nunes, Charles Washington Costa de Assis, Rita de Cássia Fonseca

5. Centralizadora Compe: Troca cheque e informações com banco sacado no mesmo dia ( $\mathrm{D}+0$, para cheques com valor acima de $\mathrm{R} \$ 299,99)$;

5.1Centralizadora Compe: Troca cheque e informações com banco sacado no dia posterior ( $D+1$, para cheques com valor abaixo de $R \$ 299,99)$;

5.2Banco sacado: Troca informações e cheque com a Compe nos respectivos prazos;

6. Centralizadora Compe: Recebe informações do banco sacado, se paga ou devolve o cheque, no prazo de D+1 (devolução);

6.1Centralizadora Compe: Recebe informações/ cheque (acatar ou devolver), em $D+1$

6.2Banco sacado: Fornece informações/ cheque com a Compe (acatar ou devolver);

7. Centralizadora Compe: No pagamento do cheque, sistema credita beneficiário e debita sacado/ emissor;

7.1Centralizadora Compe: No caso de pagamento, o cheque fica retido na câmara e depois é incinerado;

7.2Banco sacado: No caso de pagamento, tem débito gerado na conta de seu correntista;

7.3Depositante: No caso de pagamento, tem crédito gerado em sua conta;

8. Centralizadora Compe: $\mathrm{Na}$ devolução, carimba cheque com o motivo de devolução que foi informado anteriormente pelo banco sacado;

8.1Centralizadora Compe: Envia cheque para agência do depositante;

8.2Banco do depositante: na devolução, recebe cheque da compe e envia ao seu cliente;

8.3Depositante: Recebe cheque na sua agência.

Tal modelo inviabilizava a liquidação dos cheques, pois as dificuldades encontradas no transporte de cheques, na segurança dos malotes e no tempo de processamento dos documentos, acarretavam muitas vezes no descumprimento de prazos vigentes para devolução. 
Os Impactos da Reengenharia no processo de compensação de cheques: Estudo em uma Instituição Financeira João Marinho de Oliveira Filho, Rosângela Venâncio Nunes, Charles Washington Costa de Assis, Rita de Cássia Fonseca

\subsubsection{Processo após reengenharia}

A Carta Circular no 3532, de 20 de abril de 2011, determinou que os cheques deveriam ficar acolhidos nas agências em que foram depositados, cabendo as agências apenas capturarem os dados lógicos e a imagem do documento, informações necessárias para dar continuidade ao processo de compensação. A Figura 8 mostra como ficou o fluxo de cheque e informações após a reengenharia.

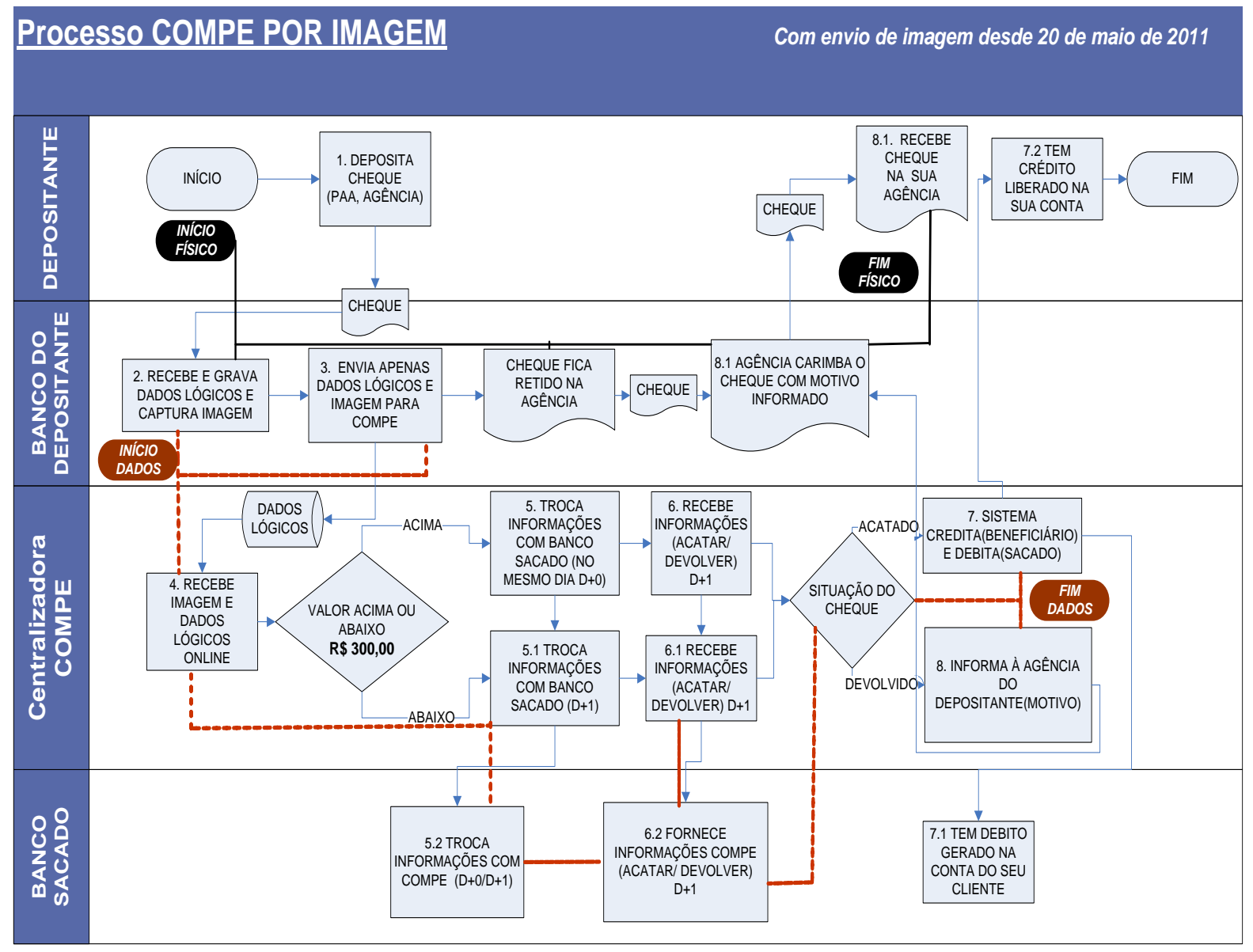

Legenda:

Fluxo (Físico)

Fluxo (Dados)

Figura 8: Fluxograma do processo de compensação de cheques após a truncagem

Fonte: Elaborado pelos autores com base nas informações coletadas com os gestores. 
Os Impactos da Reengenharia no processo de compensação de cheques: Estudo em uma Instituição Financeira João Marinho de Oliveira Filho, Rosângela Venâncio Nunes, Charles Washington Costa de Assis, Rita de Cássia Fonseca

\section{Script do processo após reengenharia:}

1. Beneficiário/ Depositante: Deposita/ apresenta o cheque na agência;

2. Banco Depositante: Recebe documento, grava dados lógicos através da banda magnética do mesmo e captura a imagem;

3. Banco Depositante: Envia dados lógicos à centralizadora de compensação respectiva à sua praça;

4. Centralizadora Compe: Recebe imagem e dados lógicos via on-line.

5. Centralizadora Compe: Troca informações com banco sacado no mesmo dia ( $D+0$, para cheques com valor acima de $\mathrm{R} \$ 299,99)$;

5.1 Centralizadora Compe: Troca informações com banco sacado no dia posterior ( $D+1$, para cheques com valor abaixo de $R \$ 299,99$ );

5.2Banco sacado: Troca informações e cheque com a Compe nos respectivos prazos;

6. Centralizadora Compe: Recebe informações do banco sacado, se paga ou devolve o cheque, no prazo de D+1 (devolução);

6.1 Centralizadora Compe: Recebe informações (acatar ou devolver), em D+1;

6.2 Banco sacado: Fornece informações para Compe (acatar ou devolver);

7. Centralizadora Compe: No pagamento do cheque, sistema credita beneficiário e debita sacado/ emissor;

7.1 Banco sacado: No caso de pagamento, tem débito gerado na conta do seu cliente;

7.2 Depositante: No caso de pagamento, tem crédito gerado na sua conta;

8. Centralizadora Compe: Na devolução, apenas informa o motivo de devolução ao banco depositante;

8.1Banco depositante: Carimba cheque com o motivo informado entrega ao cliente.

A maneira como atualmente é liquidado o cheque traz mais segurança, confiabilidade e rapidez, porque os documentos não precisam mais ser transportados 
Os Impactos da Reengenharia no processo de compensação de cheques: Estudo em uma

Instituição Financeira João Marinho de Oliveira Filho, Rosângela Venâncio Nunes, Charles Washington Costa de Assis, Rita de Cássia Fonseca

até a centralizadora, trazendo agilidade nas transmissões das imagens e dos dados dos cheques. Minimizaram-se também os custos operacionais, como por exemplo, transporte e pessoas.

\subsubsection{0 processo de mudança}

A principal característica de todo processo de reengenharia se deu pelo uso da imagem do cheque para seu processamento, oficialmente, a partir de 20 de maio de 2011, que passou a não ser mais transportado via malote (serviço de transporte aéreo/ terrestre) e muito menos destinado à centralizadora de compensação de cheques. As agências capturam a imagem do cheque através de scanners e enviam a mesma para a respectiva centralizadora, que apenas com a imagem retoma todo o processo de compensação e, para os casos de devolução, o motivo da mesma é enviado conforme é a imagem, cabendo a agência apenas carimbar o documento e devolver ao depositante. Outros fatores importantes foram as reduções de custos operacionais e o ganho de tempo nos fluxos de informações, fazendo com que o cliente passasse a ter mais confiabilidade em relação aos prazos de COMPE estabelecidos pelo BACEN.

De fato, essa mudança trouxe muitos benefícios e alguns problemas, porém, a necessidade de tornar o processo mais rápido era mais relevante. Vários funcionários das centralizadoras não conseguiram se adaptar as mudanças impostas, prejudicando, em alguns momentos, o clima organizacional.

Algumas inconsistências foram detectadas no momento de implantação do novo modelo, pois alguns funcionários tiveram dificuldades em assimilar as novas prioridades e tarefas, tanto na COMPE, quanto nas agências. Também houve a redução de cargos e postos de trabalho, a estrutura ficou mais horizontalizada, reduzindo-se em $50 \%$ o número de gerentes de grupo; em $50 \%$ o número de assistentes; e em $60 \%$ o número de escriturários.

Logo, pode-se perceber a grande complexidade da implantação dos novos modelos, tendo em vista a relação entre diversos recursos e instituições, com diferentes pensamentos e métodos. 
Os Impactos da Reengenharia no processo de compensação de cheques: Estudo em uma Instituição Financeira João Marinho de Oliveira Filho, Rosângela Venâncio Nunes, Charles Washington Costa de Assis, Rita de Cássia Fonseca

\subsubsection{Impactos da reengenharia no desempenho}

Como foi citado anteriormente, o uso da imagem do cheque para sua compensação talvez não fosse considerado uma mudança drástica a ponto de considerá-la uma reengenharia. Todavia, nesse tópico são explanados os impactos que tal reestruturação ocasionou no desempenho e demais dados que caracterizam o ambiente em estudo.

Ressalta-se a utilização de algumas medidas de desempenho mencionadas por Slack et al. (2002) no referencial teórico desse artigo. Os autores dividem os aspectos mensuráveis em cinco objetivos de desempenho, que são: a flexibilidade, a qualidade, a velocidade, a confiabilidade e o custo, sendo os quatro últimos aplicados nesse estudo.

\begin{tabular}{|c|c|c|c|c|}
\hline \multicolumn{5}{|c|}{$\begin{array}{c}\text { INDICADORES DE DESEMPENHO } \\
\text { PROCESSO DE COMPENSAÇÃO DE CHEQUES }\end{array}$} \\
\hline O que? & Antes & Atualmente & Diferença & Redução(\%) \\
\hline Número de funcionários & 60 & 18 & 42 & 70 \\
\hline Número de estagiários & 40 & 3 & 37 & 92,5 \\
\hline Número de terceirizados & 15 & 8 & 7 & 46,7 \\
\hline Número de jovem aprendiz & 2 & 0 & 2 & 100 \\
\hline Número de colaboradores indiretos & 8 & 4 & 4 & 50 \\
\hline $\begin{array}{l}\text { Número médio de } \\
\text { ocorrências de roubo } \\
\text { de malote de cheque } \\
\text { no ato do transporte. (mês) }\end{array}$ & 3 & 0 & 3 & 100 \\
\hline $\begin{array}{l}\text { Valor do contrato do } \\
\text { serviço de logística (mês) }\end{array}$ & $\mathrm{R} \$ \quad 1.000 .000,00$ & $\mathrm{R} \$ \quad 600.000,00$ & $400.000,00$ & 40 \\
\hline $\begin{array}{l}\text { Porcentagem média de devoluções de } \\
\text { cheques fora do prazo(mês) }\end{array}$ & $4 \%$ & $0 \%$ & $4 \%$ & 100 \\
\hline Utilização dos recursos & $100 \%$ & $100 \%$ & 0 & 0 \\
\hline $\begin{array}{l}\text { Tempo máximo } \\
\text { atingido para } \\
\text { processamento } \\
\text { da compensação } \\
\text { de cheques em } \\
\text { algumas localidades.(dias) }\end{array}$ & 15 & 2 & 13 & 86,7 \\
\hline
\end{tabular}

Quadro 5: Comparativo de indicadores de desempenho, antes e depois da reengenharia Fonte: Elaborado pelos autores com base no levantamento de dados no ambiente de estudo. 
Os Impactos da Reengenharia no processo de compensação de cheques: Estudo em uma Instituição Financeira João Marinho de Oliveira Filho, Rosângela Venâncio Nunes, Charles Washington Costa de Assis, Rita de Cássia Fonseca

O quadro explana a medição de dez itens que sofreram impactos com a mudança no processo. Vale ressaltar que tais itens podem se encaixar nos quatro objetivos de desempenho, conforme já citado.

O número total de colaboradores e do percentual de utilização de recursos estão relacionados ao objetivo custo, no momento em que afetam diretamente os indicadores de tempo mínimo e médio de entrega, de eficiência e de produtividade da mão de obra.

O número médio de ocorrências de roubo de malote de cheques no ato do transporte, percentagem média de devoluções de cheques fora do prazo e o tempo máximo atingido para processamento da compensação de cheques em algumas localidades, estão atrelados aos objetivos qualidade, velocidade e confiabilidade, no instante em que se assemelham ao escore de satisfação do consumidor, número de defeitos por unidade, percentagem de pedidos entregues com atraso, respectivamente. Por não ter sido feita qualquer pesquisa de satisfação do consumidor, supõe-se que a redução no extravio de documentos e o cumprimento de prazos atendem as expectativas dos clientes.

O Quadro 5 expõe as diferenças em relação ao número de colaboradores diretos e indiretos que a câmara de compensação detinha antes e após a mudança. Uma estrutura que contava com 125 pessoas passou para 33, resultando numa redução de $73,6 \%$, inclusos em folha de pagamento, benefícios, contratação de mão de obra terceirizada, segurança, manutenção predial, entre outros. Os dados mostram a economia de recursos que a instituição financeira passou ter com o departamento.

Um indicador minimizado foi o de ocorrências de roubos de malotes, ou seja, os cheques eram extraviados no deslocamento entre agência e centralizadora, entretanto, com a reengenharia os cheques não precisaram mais sair da agência, mitigando as ocorrências de roubos de malotes, atingindo diretamente o cumprimento dos prazos e, consequentemente, a satisfação dos clientes.

Outro ganho percebido foi o reajuste no valor do contrato de transporte logístico que a instituição detinha com a empresa responsável. O valor que era pago por tal serviço chegava a representar $R \$ 1.000 .000,00$ por mês, reduzindo para $R \$ 600.000,00$ 
Os Impactos da Reengenharia no processo de compensação de cheques: Estudo em uma Instituição Financeira João Marinho de Oliveira Filho, Rosângela Venâncio Nunes, Charles Washington Costa de Assis, Rita de Cássia Fonseca

após as mudanças implementadas. A diferença principal é que antes mais de $50 \%$ do que era transportado eram cheques, tendo ainda que contar com serviços de deslocamento aéreo em algumas regiões, hoje esse transporte acontece com bem menos volume, levando apenas material de expediente, outras correspondências e outros objetos, significando mais uma economia nos custos de produção que a instituição financeira passou a ter.

A reengenharia ainda impactou em outras despesas como, por exemplo: valor da tarifa de energia, água e esgoto e a taxa de manutenção predial. Não se mensurou esses impactos, pois no mesmo prédio existem ainda dois departamentos distintos, mas da mesma instituição financeira. Apesar da COMPE historicamente utilizar as 24 horas do dia para operacionalizar, os outros setores operam apenas durante o dia, deixando assim desproporcional o rateio entre tais despesas, que são divididas por três, sem levar em conta o consumo efetivo dos ambientes.

De tal modo, o elemento que mais pesou para as finalidades de atendimento e satisfação do cliente foi a redução dos enormes prazos de compensação de cheques, pois localidades mais distantes dos grandes centros tardavam até 15 dias para compensar seus cheques por motivos de deslocamento. Hoje, com o uso da imagem para a compensação, tem-se a resposta em até três dias dependendo do horário do depósito.

Considera-se de suma importância ter sido realizada a mensuração do desempenho antes e após o processo de reengenharia, o que possibilitou fazer-se uma análise comparativa entre os dois estágios vivenciados pela instituição estudada.

\section{CONSIDERAÇÕES FINAIS}

Esse estudo ratificou a importância de analisar os impactos originados por qualquer mudança em processos ou mesmo por uma reengenharia. Revelou que tais avaliações permitem um maior controle das atividades e dos recursos por parte das organizações. 
Os Impactos da Reengenharia no processo de compensação de cheques: Estudo em uma Instituição Financeira João Marinho de Oliveira Filho, Rosângela Venâncio Nunes, Charles Washington Costa de Assis, Rita de Cássia Fonseca

Nesse sentido, entende-se ter sido possível alcançar o objetivo proposto, que era o de identificar os impactos da utilização da reengenharia de processos no desempenho, considerando o processo de compensação de cheques em uma instituição financeira.

O estudo realizado também permitiu concluir acerca do mencionado na introdução, de que a reengenharia poderia mitigar inconsistências, reduzir custos e diminuir o tempo de processamento de compensação de cheques.

Com o suporte do referencial teórico e com a coleta de dados na instituição, o estudo conseguiu responder ao problema mencionado no início, que indagava sobre os impactos gerados após a utilização da reengenharia de processos em uma centralizadora de compensação de cheques. Percebeu-se que mudanças primeiramente previstas para trazer melhorias para o cliente, acabaram trazendo melhorias também para a organização, por meio da redução de custos e minimização de erros, agregando, assim, valor aos clientes.

É notório, também, que os gestores devem sempre agir de maneira sistêmica, pois nesse caso exigências externas provocam demandas para reestruturações internas, considerando que as organizações estão sujeitas a diversos fatores que podem impactar ou alterar seus objetivos.

O estudo realizado pode servir de fonte de pesquisa para estudos futuros, uma vez que além de tratar de assuntos contidos no referencial teórico (gestão de processos, reengenharia de processos, avaliação de desempenho, impactos da reengenharia na avaliação de desempenho), ainda apresenta um resgate histórico do processo de compensação de cheques no Brasil, mas com foco nas últimas mudanças, avaliando os impactos da reengenharia de processos em uma instituição financeira.

\section{REFERÊNCIAS}

ARAUJO, L. C. G. de. (2011). Organização, sistemas e métodos e as tecnologias de gestão organizacional. (5 ed.). São Paulo: Atlas. 
Os Impactos da Reengenharia no processo de compensação de cheques: Estudo em uma

Instituição Financeira

João Marinho de Oliveira Filho, Rosângela Venâncio Nunes, Charles Washington Costa de Assis, Rita de

Cássia Fonseca

BANCO CENTRAL DO BRASIL. Carta Circular $n^{\circ}$ 3532. Disponível em: $<$ https://www3.bcb.gov.br/normativo/detalharNormativo.do?method=detalharNormativo\& $\mathrm{N}=111028178$ > . Acesso em: 07/fev/2013.

BEUREN, I. M. (2006). Como elaborar trabalhos monográficos em contabilidade. São Paulo: Atlas.

CAMPOS, J. A. (1998). Cenário balanceado: painel de indicadores para a gestão estratégica dos negócios. São Paulo: Aquariana.

CHEQUE. Imagem de cheque com banda magnética. Disponível em: $<$ www.osegredo.tv>. Acesso em: 25/mai/2013.

CHIAVENATO, I. (1994). Manual de reengenharia. São Paulo: Makron Books.

CORRÊA, H. L; CORRÊA, C. A. (2011). Administração da produção e operações. (2 ed.). São Paulo: Atlas.

COSTA, Z. M. da. (2003). A história da compensação de cheques e outros papéis no Brasil de 1921 à 2002. Rio de Janeiro: Gráfica do Banco do Brasil.

CURY, A. (2012). Organização e métodos. (8 ed.). São Paulo: Atlas.

KAPLAN, Robert S.; NORTON, David P. (1997). A estratégia em ação. Rio de Janeiro: Campus.

MAXIMIANO, A. C. A. (2012). Teoria geral da administração. São Paulo: Atlas.

MANUAL OPERACIONAL DA COMPE. (2011). Centralizadora de compensação de cheques. FEBRABAN: Brasília.

NADLER, D. et al. (1994). Arquitetura organizacional. Rio de Janeiro: Campus.

OLIVEIRA, S. B. de. (2008). Gestão por processos. (1 ed.). São Paulo: Qualitymark.

OROFINO, A. C. (2009). Gestão estratégica: processos com resultado. São Paulo: LTC.

PADOVEZE, C. L. (2005). Controladoria: estratégica e operacional. São Paulo: Thomson.

SILVA, E. L. da; MENEZES, E. M. (2001). Metodologia da pesquisa e elaboração de dissertação. Florianópolis: Laboratório de Ensino a Distância da UFSC. 
Os Impactos da Reengenharia no processo de compensação de cheques: Estudo em uma Instituição Financeira João Marinho de Oliveira Filho, Rosângela Venâncio Nunes, Charles Washington Costa de Assis, Rita de Cássia Fonseca

SLACK, N. L. et al. (2002). Administração da produção. (2 ed.). São Paulo: Atlas.

SORDI, J. O. de. (2005). Gestão por processos. São Paulo: Saraiva.

Data de Submissão: 06/03/2014

Data de Aceite: 23/07/2014 